\title{
Importance of Parental Involvement to Meet the Special Needs of their Children with Disabilities in Regular Schools
}

\section{Doriana Balli}

PhD. Candidate; d-ball@hotmail.com

\author{
Doi:10.5901/ajis.2016.v5n1p147
}

\begin{abstract}
Inclusive education for special needs students is an important component of their inclusion into society. Despite the other conditions that school must create, in order to fulfill the rights for education of children with disabilities, the role of parental engagement is crucial to realize inclusive education. The Law on Pre University Education in the Republic of Albania has reinforced the importance of parental involvement in order to ensure the progress of education for students with disabilities. The fundamental aim of this study was to evaluate the level of parental involvement of 32 parents of special need children, from seven different schools of Korça region. To realize this study is used the snowball sampling method, according to which the first group of interviewed parents recruits other parents to be part of it. The qualitative method was used to analyze the data gathered from this study. The main research questions were: How does the school involve parents in school life? Are the parents satisfied with the special needs assessment procedure? How much are they represented in the school structures and do they feel part of decision - making process? As a conclusion, in practice parents were not involved enough into the school life in order to ensure the inclusion of their children within the regular education system. Parental involvement in school takes a significant sense in terms of achieving inclusive education for their children with disabilities, who could not raise the voice to protect their own rights.
\end{abstract}

Keywords: parental involvement, disability, inclusive education, school achievement

1. Introduction: Inclusive Education Approach and the Challenges that Accompany Its Implementing Process in Albania

In Albania, we are far away the realization of international standards for a comprehensive and effective education for special needs children, but it is evident the effort and a positive model created through the implementation of projects undertaken by NGOs in partnership with the Ministry of Education and Sports.

The ratification of the United Nations Convention on the Rights of Persons with Disabilities by Albanian state, set another progress in determine the institutional liabilities to create the necessary conditions to include the special needs children in regularly education.

Disabled children are one of the most excluded groups in terms of benefits they should enjoy by the educational system (UNESCO, 2006). Inclusive education is a precondition for the development of equal opportunities for education and social inclusion (Radoman, Nano, Closs, 2006). In accordance with the international and national laws students with disabilities must be placed in the so-called "least restrictive environment". A lot of studies have evidenced that inclusive education brings benefits not only for the students with disabilities and their families, but also for the teachers, other students and the whole community. It also aims at helping regular classes' students to accept their classmates with disabilities and help them to succeed, but the limited knowledge the students of mainstream schools have on various kinds of disabilities, contributed to the decline of acceptance.

Even though legal and political framework is a good one, there are observed some problems in its implementation. One of the main obstacles to realize the inclusive education in practice is the legislative gap, the lack of regulations and financial resources. Based on the research report "Analysis of the legal framework guaranteeing the education of disabled children under the inclusive education: 2005: p 38" - there are no normative acts that actually regulate the work of teachers through the IEP-s (Individualized Education Programs). The legal base on implementation of legislation on allinclusive education at the secondary schools is still unclear.

There are also no regulations for the preparation of IEP-s, for providing transportation or the other necessary conditions and infrastructures for the education of children with disabilities (Alternative Report of the UN Convention for the Children's Rights, 2009). 
Other factors that affect the effectiveness of inclusive education process are: academic curricula, teaching programs and school texts. The curricular changes should aim the inclusiveness and education for all the students (Forbes, 2007).

In order to develop inclusive policies, cultures and practices the contribution of all school stakeholders is needed. The attitudes and the role of adults, play a key role to the attitudes and behaviors of classmates and the school staff in this respect. Besides benevolent teacher's attitudes towards inclusive education issue, it depends a lot on the parental pressure toward educational policy (Meijer, Pijl \& Hegarty, 1997:28). The school thinks that parents are expecting too much given their child's abilities, while the parents accuse the school of focusing on their child's limitations (Russell, 2003).

\section{Importance of Parental Involvement and their Role to Support their Special Needs Children Education Process}

In order to achieve the needed success to the implementation of inclusive process for special needs children in regular schools, the role of parents is evaluated as irreplaceable. From the Gerber \& Popp's research (1999), comes that as a result of collaboration with the teachers, parents notice positive impact at their children who frequent regularly school. They notice significant improvements such as satisfaction, self-esteem and their children abilities to learn better.

Parents play a major role in challenging of the dynamic inclusion process that starts with the parents' decision to place their child in a mainstream setting. One of the main aspects of parent's involvement in educational process is related to their participation in drafting the IEP, not simply by signing a document prepared by the teacher.

Individual planning, as a partnership tool in the education of persons with disability, also highlights the inclusion concept (Booth, Ainscow, Black-Hawkins, Shaw, \& Vaughan, 2000).

Hoover-Dempsey and Sandler $(1995,1997)$ believe that the role and responsibilities that parents define for them is central in terms of parents' involvement. Only parents, who believe in their role to be active, are inclined to become involved in education and school matters.

They must be informed and convinced on the importance of their involvement. They should have opportunities to get all necessary information about the services and the possibilities offered by school to meet the needs of their children. Based on the law in force, it is foreseen the establishment of a multidisciplinary school commission to evaluate the children needs and to propose the most suitable schools, but the final decision for choosing the school belongs to parents. It is parents' right to be part of every decision-making that affect the welfare of their children. Another important component that influences the parent involvement into school is teachers' commitment. From a study conducted by Peña (2001), the most powerful recommendation is 'make the parent feel more welcome' (p. 52). For a number of reasons, teachers might display a rather reserved attitude towards parent involvement (Hoover-Dempsey et al., 1992; HussKeeler, 1997). In some cases there are noticed conflictual relationships between teachers and parents, what influence the level of involvement. Not every child enters in school identified with a disability and often happens that the parents refuse to accept the difficulties of their children even after a professional assessment. This is the moment when teachers should be considered part of the acceptation process and do not consider their irritation as personal; this is the moment when misunderstandings should be avoided.

Epstein (1992) has defined 6 types of parental involvements, starting from the asisstence of the parents to improve parenting skills up to their involvement in decision-making processes and the collaboration with school community. Parents might choose a specific form of involvement, depending on their skills and opportunities, or according the school needs.

A meta-analysis conducted by Fan and Chen (2001) confirmed the correlation between parental involvement and the academic results of their children. Other facts indicate the opposite relationship, that high results of children may encourage a greater parent involvement in school issues. Unlike integration, inclusiveness means that school must establish the needed conditions for the development of potentials of the children who study there taking into account any particular need they may have. This conclusion is based on the way the social model considers disability like something imposed on top of our impairments by the way we are unnecessarily isolated and excluded from full participation in society (Oliver, 1996). In this respect, among others, inclusiveness depends on society itself and in particular on the pressure of parents to include their children into society.

Having a disabled child brings difficulties such as: loose of incomes, isolation from the community and other psycho-social problems. Parents also face difficulties in matching their private and professional life when they looked after their "dependent" children. It is the time that even in Albania, parents' voice should be listened more, because 
without the pressure of parents no changes of educational policies and the improvement of legal frame could occur.

\section{Methodology}

\subsection{Research aim and objectives}

This research aims at gathering parental perceptions with regard to their involvement in schools as an important condition that facilitate the education process of their children with disabilities.

The main objectives are:

1. To explore parents' information level on legislative framework that sanctions the children rights for education and its implementation;

2. To assess parental involvement and their points of view on different issues regarding children education process as well as identify areas that need improvement;

3. To evaluate the level of parents' satisfaction with regard of school procedures and policies to involve them especially in terms of needs assessment and composing IEP;

The main research questions to gain parents' opinions were focused on these issues: How are they getting informed and invited to be included in school life? Are they being informed on the current law and who help them to update their knowledge on the education policies for the children with disabilities? Which is the procedure that is used to help parents get information on their children progress and opportunities of development? How are they represented in the school structures and in the education planning process for their children? Are parents satisfied with the special needs assessment procedure and the design of Individual Education Plan?

\subsection{Participants}

This study targeted 32 parents of children with different disabilities that frequent regularly secondary schools in an urban or rural area. To realize this study is used the snow ball sampling, by which the parents of disabled children bring other parents who gratify the attributes required in this study. Some of them were also members of a parental association that works to protect the Rights of Persons with Disabilities. One of the focus groups (7 persons) was composed by members of this association, and one other focus group was composed of parents of the schools setting in rural area. Only two male parents were part of this study, which indicates the great responsibility of mothers in fostering and educating their children, which is more evident in cases when children suffer diverse disabilities. All participants were females aging from 24 to 50 .

\subsection{Data collection and analysis}

To analyze the qualitative data of interviews prior it was drafted a list of codes (Strauss, 1987), in order to simplify and focus on particular characteristics seen in the data of focus groups. Analytical coding, which was used in the current study, allows the researcher to categorize or develop patterns from the data (Richard \& Morse, 2007) by grouping the participant's words into themes (Bogdan \& Bilken, 2003). Qualitative method was used to analyze the data collected by focus groups. Conducting of focus groups helped the participants to express their opinions and understand that they aren't alone in their confrontation with education's problems of their children. This made it possible to establish a clear picture of parent's involvement and their perceptions and information about inclusive education.

\section{Results and Discussion}

Different studies have shown that if parents participate regularly in school they will gain a better understanding of school's aims, methods, and will feel more closely involved. The findings of this study demonstrate how valuable parents are in the education process of their children, but many parents feel that the school does not listen them enough or does not keep them sufficiently informed on how their children's needs are being met (Lindsay and Dockrell, 2004). In this study also resulted that most parents find it difficult to create an impression of the methods used by teachers to include their children in class during the education process.

$53.13 \%$ of the interviewed parents stated that in principle, school encourages parental involvement, but the desired level of parental involvement is not achieved in practice. This was the opinion of all 7 parents coming from the rural 
schools.

$31.25 \%$ said that the school had neither policies nor practices to involve the parent, and only 5 of them (15.63\%) feel more involved in school to contribute to their children education process.

Regarding the issue of how they get this information on their children rights and needs resulted that 6 of them $(18.75 \%)$ were informed through the association's trainings on the legislation and what really it provides and as a result they were more interested to be ensured that their children receive a good education.

By the data of focus groups resulted that majority of parents (65.63\%) never got informed from the school staff on the legislation and school policy that facilitates the education of children with disabilities. Six of the parents were informed by the school staff about legal framework, 3 from whose get this information by the specialists of the school psycho-social service and 5 or $15.63 \%$ others was mainly informed by external experts, internet, or consultations with other school parents of children with disabilities.

From 32 parents of the children with disabilities only 4 were part of school structures: members of school council or school board, from whose, two were the member of parents association.

$62.5 \%$ of parent said that the school doesn't have clear policies to invite parents in decision-making process so they feel more excluded from the school life.

An important thing that this study emphasizes is the satisfied level of awareness and knowledge of parents that are members of the association of children with disabilities.

The parents that found themselves more involved in school, $15.63 \%$ declared that this was an important factor which influences their children success in school.

"When parents are interested on children education process, teachers also increase their attention doing the best with children by involving the parents in this issue"-said one of them.

This is also confirmed by some researchers who have claimed that greater parental involvement could contribute to a higher academic achievement of the child (Eccles and Harold, 1993; Georgiou, 1999). Approximately half the interviewed parents were dissatisfied with the procedures of the needs assessment of their children with disabilities by school commission. The results indicated that the assessment commission didn't present realistically the needs for support to the children with disabilities. It is important for school to have a clear map of children needs and addressing them in appropriate public structure in order to ensure a qualitative education for children with disabilities. Eighteen parents declared that schools didn't take into consideration their opinions because of the limited budgets and the impossibilities to meet these needs by themselves. This emphasizes again the vital role of the parents' pressure to be meaningfully involved in the development and implementation of education policies for children with disabilities.

Regarding the composing of IEP, $78.13 \%$ of parents always attended the IEP meetings for their child (7 of them had never been part of IEP meetings), but only $31.25 \%$ of parents indicated that they were treated as equals and teachers were willing to considerate their inputs in this commission. The approximately $59.4 \%$ of parents said that educators did not understand their child's needs and noted that a considerable number of objectives created during IEP meetings were not fulfilled.

Other participants, 15 of them, indicated that they were not included in the process of developing goals for their son or daughter, which is consistent with previous research (Frankl, 2005 \& Fish, 2008). They felt that the IEP meeting was merely a formality "I just fill the IEP s presented to me to sign" one of the participants said.

\subsection{Teacher - Parent Communication}

Many teachers have negative attitudes toward students with disabilities because they do not know how to teach them (Clark, French and Henderson, 1986). On the other hand, parents are the main source of information for their children's performance at school, so the teachers can facilitate it by keeping regular contacts with parents through telephone calls, home -visits, home -school notebooks, weekly report, forms of liaison (Hornby, 1995). From the data gathered by parents opinions resulted that teachers are often disappointed because some parents do not come to parent-teacher meetings at school, but they don't understand that maybe this is related to their negative experience in other meetings. Parents could provide crucial information regarding their child's strengths and challenges. By creating a warm and welcoming atmosphere, educators can truly connect with parents early on in the process. Educators and parents can then become partners in the students' learning. 


\section{Conclusions and Recommendations}

Education is a key component in fighting poverty and social exclusion of people with disabilities and their families. In order to obtain an effective and inclusive education system for children with disabilities is important to undertake a lot of interventions. The main arrangements consist of a greater financial support, teacher trainings, curriculum adaptation, assistant teachers, changing of negative attitudes etc. The role of parents is imperative and unique in the implementation of inclusive education for children with disabilities. Parental involvement in education is a broadly concept, because it emerges and is fulfilled in different manners. They have essential responsibilities for education and social development of their children. Parents should raise the awareness of teachers, neighborhoods, and whole community on their children's rights. In this respect, parents and teachers should coordinate their attempts to create a positive climate, where children feel secure, accepted and included. The entire legal framework that guarantees the education of children with disabilities and learning disabilities recognizes the central and irreplaceable role of parents in children education. Parental involvement in school life should be the key priority of the planning process and must be encouraged constantly. This is especially important in the context of the schools as community's centers, where the family and community cooperation is considered as vital. It's in parents' interest to establish a hospitable and more inclusive society for their children.

The law 69/2012, articles 62 and 102 of Normative Provision of Pre University Education highlights that parents are holders of the rights and they should being informed on legal framework, regulation, safety conditions, to give consent for the complementary activities organized by school etc, so the school should understand that not only the needs of student with disabilities are diverse, but the parents' needs also differ.

On the other hand, parents have the responsibility of being open and honest and to inform the staff about the difficulties of children and also to participate actively in the drafting and reviewing of IEP process. Students of "Involved parents" are more likely to graduate and go on to postsecondary education (Henderson \& Mapp, 2002).

Different studies have shown that when school and parents work together to support learning, children tend to do better in school. Most parents want to know how their children are getting on at school, and they appreciate receiving guidance from teachers to deal with specific difficulties. If educators take into account the parent's opinions into the development of an IEP, this will enhance feelings of collaboration between parents and educators. Parents play a crucial role in developing the Individualized Education Program (IEP), which cannot be implemented without parents consent.

Results from this study also indicated that parents feel they should be more involved in the process of preparing the objectives of IEP instead of just signing the document.

School should develop procedures and practices to inform parents of children with disabilities and involve them being part of school structures, which play an important role in school decision making process (as a group of interests). The school staff, teachers and the workers of school psycho-social services should support parents, even though they may not ask for it. Family visits are a good manner to see how parent cope with their children at home when they feel more comfortable; It is important to empathize with parents and try to understand their perspectives. Parents should not be indifferent in their demands and pressure for the implementation of legal framework by all school actors; they have the right to choose and be chosen in school structures. Involvement in parents associations or professional organization is a good source for parents getting informed and sharing their experiences.

\section{References}

Armstrong, F., (2003). Spaced Out: Policy, Difference and the Challenge of Inclusive Education. USA

Dimitrios, K., Georgia, V., Eleni, Z., Asterios, P. (2008). Parental Attitudes Regarding Inclusion of Children with Disabilities in Greek Education Settings, Electronic Journal for Inclusive Education, 2 (3)

Dockrell, J.E. and Lindsay, G. (2004) Whose Job Is It? Parents' Concerns about the Needs of their Children with Language Problems Journal of Special Education Vol. 37, 2004

Ballhysa, N., (2011). Inclusiveness of special needs children in Albanian school": Tirane

Booth, T., Ainscow, M. (2004). Index for Inclusion, Developing Learning, Participation and Play in Early Years and Childcare. Centre for Studies on Inclusive Education, 2-nd, Bristol.

Booth, T., Ainscow, M., Black-Hawkins, K., Shaw, L. \& Vaughan, M. (2000). Index for inclusion.

Bogdan, R. C \& Biklen, S. K. (2003). Qualitative Research for Education: An introduction to Theories and Methods (4th ed.). New York: Pearson Education group. (pp. 110-120).

Developing learning in participation and schools. Bristol, England: Centre for Studies on Inclusive Education (CSIE).

Epstein, J.L. 2001. School, family and community partnerships. Boulder, CO: Westview Press.

Forbes, F. (2007) "Towards inclusion: an Australian perspective'. Support for Learning, 22 (2), 66-71

Ikonomi, E., Musai, B. \& Sotirofski, K. (2010) Mapping policies and practices for the preparation of teachers for inclusive education in 
contexts of social and cultural diversity: Albania, Country Report. Working Paper. European Training Foundation

Russell, F. (2003). The expectations of parents of disabled children. British Journal of Special Education, 30, 144-149.

H. Blok, T. T. D. Peetsma, E. Roede .(2007). Increasing the involvement of parents in the education of special-needs children. Journal of Developmental Disabilities: Vol. 53, No. 104, pp. 3-16

Muller, C. (1993). Parental involvement and academic achievement: An analysis of family resources available to the child.

Mackichan, M. D., \& Harkins, M. J. (2013). Inclusive Education: Perceptions of Parents of Children with Special Needs of the Individual Program Planning Process, Electronic Journal for Inclusive Education, 3 (1).

Oliver, M. (1996). Understanding disability: from theory to practice. Basingstoke: Macmillan.

Schneider, B., Coleman, J. S. (eds.), Parents, Their Children, and Schools, Westview, Boulder, CO, pp. 73-113.

Payne, M. (2005). Modern Social Work Theory:3-rd edition

UNESCO (2005) Guidelines for Inclusion: Ensuring Access to Education for All Children. Paris

Law 69/2012 on Pre University Education System in the Republic of Albania

MAS.(2013). Normative Provision of Pre University Education System. Tirane, http://www. medpak.org/ MEDPAK, 'Defending the Rights of People with Disabilities' accessed 09/01/2016 